\title{
The Most-Favored Nation Rule in Club Enlargement Negotiation
}

\author{
EDWIN L. C. LAI \\ Research Department \\ Working Paper 0815
}

Federal Reserve Bank of Dallas 


\title{
The Most-Favored Nation Rule in Club Enlargement Negotiation
}

\author{
by
}

\author{
Edwin L.-C. Lai*
}

October 2008

\begin{abstract}
We study the effects of the Most-Favored Nation rule in an applicant's negotiation to join a club. When the applicant has to carry out a series of bilateral bargains with the existing members, we find that there are two effects of the MFN rule, viz. the hardened bargainer effect and the free-rider effect. The former effect tends to favor the applicant, while the latter effect tends to hurt the applicant. We find that the free-rider effect is stronger the more asymmetric are the members. The hardened bargainer effect is stronger the larger is the "size of the pie". As the number of members increase, it is more likely that the hardened bargainer effect would dominate.
\end{abstract}

JEL Classification Number: L14, F13, C78

Keywords: bargaining, club enlargement, most-favored nation, WTO, accession

${ }^{*}$ Research Department, Federal Reserve Bank of Dallas, P O Box 655906, Dallas TX 752655906, USA. Tel. 1-214-922-6941; Fax. 1-214-922-5194; email: Edwin.L.Lai@gmail.com and Edwin.Lai@dal.frb.org. I thank Rick Bond for his insightful comments at various stages of the paper. Thanks also to Quan Wen, Larry Qiu and participants in seminars in Hong Kong, including Lingnan University, Baptist University, and City University of Hong Kong, the Econometric Society European Meeting in Madrid, and Midwest Economic Theory Conference in IUPUI, Indiana. I gratefully acknowledge the support of the work in this paper by the Research Grants Council of Hong Kong, China (Project no. CityU 1235/00H). The support of this work by the Research Center for International Economics at City University of Hong Kong is hereby gratefully acknowledged. The views expressed in this paper are those of the author and do not necessarily reflect those of the Federal Reserve Bank of Dallas or the Federal Reserve System. 


\section{The Most-Favored-Nation Rule in Club Enlargement Negotiation}

\section{Introduction}

In the world economy, countries very often form clubs with each other. Club members usually confer mutual benefits to each other through granting exclusive concessions to each other. Because member countries can be very different in size and stage of development, many clubs allow different members to grant different levels of concessions to the rest of the club. However, the most-favored nation (MFN) principle usually applies. According this principle, each country must grant the same concession to all other members of the club. In other words, a country cannot discriminate between any two member countries. Typically, when an outside country wants to join a club, it has to conduct a series of bilateral negotiations with the existing members of the club to determine the MFN concessions it has to make to each member of the club. A good example of a club is the World Trade Organization (WTO). Other examples are free trade areas such as the North American Free Trade Agreement (NAFTA) and the proposed Free Trade Area of Americas (FTAA). In these clubs, the club enlargement or accession negotiation process are similar — a series of bilateral negotiations are conducted between the applicant country and the existing members of the club. In the end, usually a (virtual) consensus is required for accession. (See, for example, WTO 1995a, b and 2005.) $)^{1}$

Take the example of the accession to the WTO. According to the rules of the WTO, when a non-member applies for accession, it has to first propose a set of tariff reductions to all members of the Working Party, which consists of all the interested members of the WTO. These countries usually include all the large trading countries in the WTO. After that, the applicant has to conduct a series of bilateral market-access negotiations with each member of the Working Party. Normally, the tariff commitments of members would be fixed

\footnotetext{
${ }^{1}$ In a free trade area, though tariffs between any two members are typically set to zero, other aspects of market access may not be completely free of barriers. For example, in the NAFTA, aspects of market access other than tariffs including investment, access by service providers, government procurement, intellectual property rights, and capital control have to be negotiated among the members. However, even in these areas, the MFN rule applies. The situation is similar in the proposed FTAA. See their website at http://www.ftaaalca.org/alca_e.asp.
} 
by previous rounds of WTO/GATT negotiations, and would not be altered in the accession negotiations. At the conclusion of this series of bilateral negotiations, the applicant would usually have satisfied all the members of the Working Party. (See WTO 1995a, b and 2005.)

The objective of this paper is to explore the effects of the MFN rule on the degree of concession made by the applicant in the accession process: Would the applicant make more concessions when MFN is required to be implemented immediately than when MFN is temporarily exempted during the transition? What is the impact of the MFN rule on the distribution of payoffs among the acceding country and the existing member countries? The MFN principle is widely accepted in multilateral agreements firstly because it is perceived as "fair" as it is non-discriminatory; secondly, it is easy to implement due to its simplicity. It is therefore no wonder that MFN is a widely adopted rule in club enlargement negotiations. However, we believe it is still worthwhile to explore the counter-factual cases of non-existence of MFN rule, because it would help us understand the implications of the existing rules, and to introduce remedies if some consequences of the existing rules are found to be undesirable. There are indeed provisions for temporary exemptions of MFN in the WTO. For example, in the General Agreements on Trade in Services (GATS) negotiations under the auspices of the WTO, many countries asked for temporary exemptions to the MFN rule. The GATS indeed permits five to ten years of exemptions. Would the requirement of MFN in the accession negotiations confer disadvantages to an acceding country? Or, what is the same question, Would the applicant liberalize trade more from a temporary exemption from MFN? ${ }^{2}$

The literature on the effects of the MFN rule on tariff negotiaton between members of a club such as the WTO is quite rich. See, for example, Caplin and Krishna (1988), Ludema (1991), Horn and Mavroidis (2001) and Saggi (forthcoming). For example, Saggi uses a "competing supplier model" similar to the one explained in the appendix, and finds that enforcing the MFN rule on tariff reduction among existing members yields higher aggregate welfare than non-enforcement of MFN. However, the literature on the effects of the MFN rule on accession negotiation is very thin.

We begin our analysis with a simple three-country model, where country 3 applies to join a club currently formed by countries 1 and 2. We compare the two rules of accession negotiation: the applicant conducting a series of bilateral negotiations with the requirement

\footnotetext{
${ }^{2}$ We do not consider the situation when an acceding country has pre-existing free trade agreements with some members of the club. In such cases, the motivation of whether or not to seek exemption from MFN would be different from what is discussed in this paper.
} 
of MFN and without MFN requirement. We use the Nash bargaining model to capture the negotiation process. Later in the paper, we generalize to the case with $n$ countries.

The MFN principle says that any market access concessions offered by the applicant to any member has to be automatically granted to all existing members. This implies that any deal that an applicant makes with a member country can be made more unfavorable to the applicant country by subsequent negotiations with other countries. In other words, the member countries with weaker bargaining positions can free-ride on the member country with the strongest bargaining position. We can call this free-rider effect. On the other hand, when an applicant gives up a dollar's worth of concession to a member country, it must be prepared to give up the same concession to each and every member. This would harden the applicant's bargaining position. Since all parties have the foresight to realize this fact, it translates into a more favorable bargaining outcome for the applicant country. We can call this hardened bargainer effect. Because these two effects tend to counteract each other, it is not immediately clear whether the applicant would benefit or be disadvantaged by the existence of the MFN rule. Our analysis shows that the free-rider effect is stronger the more asymmetric are the members (i.e. the more uneven is the distribution of the costbenefit ratios of the members under $\mathrm{MFN}$ ). If the member countries are symmetric, the free-rider effect disappears, and the applicant is unambiguously favored by the MFN rule. Moreover, if the total surplus to be divided (the "size of the pie") is sufficiently large, then the hardened bargainer effect would also dominate. When we generalize to the case with $n$ countries, we find that it is more likely for the hardened bargainer effect to dominate as $n$ increases. One policy implication of this paper is that allowing the acceding country to be temporarily exempted from the MFN requirement might in fact induce the acceding country to make more trade concessions. Thus, allowing a process of gradually phasing in the MFN requirement not only helps the acceding country to adjust but also helps trade liberalization.

The economic intuition behind our result concerning the hardened bargaining position of a central player (repeat player) in negotiations with a number of non-central players (nonrepeat player) can be traced to the study of collusive practice in the industrial organization literature. Cooper (1986), Salop (1986) and Cooper and Fries (1991) pointed out that a contractual clause, known as most-favored-customer (MFC), can be used by firms to facilitate collusion. When a firm grants MFC to its customers, it guarantees that the customers will get the lowest price among all its customers. They argue that MFC increases the cost of price competition and, hence, facilitates collusion. In other words, firms can benefit from guaranteeing the customers the lowest price. 
Our results also run parallel to those found in the law and economics literature. For example, Spier (2002) suggested that the MFN clause in out-of-court settlement negotiations between a single defendant and many plaintiffs can commit the defendant to get tough in the earlier negotiations and allows her to gain a higher share of the bargaining surplus. However, it can backfire if a later plaintiff turns out to have a much stronger case than the other plaintiffs. This is very similar to our two effects - the applicant country benefits from being tough because of the commitment effect of MFN, but it is hurt if there exists a member country which has very strong bargaining position because it needs to be compensated a lot before it is willing to settle a deal with the applicant, and that deal has to be given to everybody else according to MFN.

Another interesting and novel result of this paper is that, as the number of countries increases by duplication of existing types of member countries, it is more likely that the hardened bargainer effect dominates the free-rider effect. Therefore, bilateral negotiations with MFN is more likely to favor the applicant country as $n$ increases. That means the existing rule of accession negotiation in most international trade blocs, where bilateral negotiations with MFN are conducted, is more likely to favor the applicant (and thus induce less trade liberalization from the applicant) in a large club than in a small one.

In section 2, we lay down the assumptions and preliminary features of the model. In sections 3 and 4 we analyze bilateral negotiations with and without MFN, respectively. In section 5, we compare the outcomes of the two regimes discussed in sections 3 and 4 , and then deduce the hardened bargainer effect and free-rider effect that contribute to the different negotiation outcomes. Section 6 discusses a generalization to the n-country case. Section 7 concludes.

\section{Preliminaries}

Suppose country 1 and 2 have already formed a club, and country 3 wants to join it. Suppose the effect of country 3 joining the club is that country 3 benefits, but countries 1 and 2 have to give up something. In other words, the benefits to country 1, 2 and 3 before the applicant makes any concessions to the existing members in return, are respectively

$$
U_{1}<0, U_{2}<0, U_{3}>0
$$


and

$$
U_{1}+U_{2}+U_{3}>0
$$

where $U_{i}(i=1,2,3)$ is country $i$ 's gain due to country 3 joining the club. Note that we assume that country 3 gains while all existing members lose before country 3 makes any concessions in return. A concrete example of this process is WTO accession. When a country joins the WTO, it normally benefits from being a member. The benefits normally come from the applicant country being able to access the markets of the existing members. On the other hand, by having a new country joining the WTO, existing members have to grant market access to the applicant, which is considered (or perceived as) a loss to these countries, at least in the political sense. The accession of a new country in the WTO, however, is assumed to be globally efficiency-enhancing so that aggregate world welfare increases. Therefore, $U_{1}+U_{2}+U_{3}>0$. We call $U_{3}$ the benefit of the accession to the applicant, while $\left|U_{1}\right|$ and $\left|U_{2}\right|$ are called the costs of the accession to the members.

Let $T_{i}$ denote the extent of market opening of country 3 to country $i=1,2$. The extent of market opening determines how much country $i$ gains (and how much country 3 loses) from such a market opening policy. A concrete example of $T_{i}$ is the reduction in specific tariffs of goods imported from $i$ to 3 . We assume that if country 3 gives MFN treatment to countries 1 and 2 , then $T_{1}=T_{2}=T$. We want a model that captures the following features:

(1) $\partial W_{3} / \partial T_{i}<0$ for $i=1,2$. That is, the acceding country loses from making concessions.

(2) $\partial W_{i} / \partial T_{i}>0$ for $i=1,2$. That is, each member gains from getting the acceding country's concessions.

(3) $\partial W_{j} / \partial T_{i}<0$ for $i=1,2$ and $j=1,2$ and $i \neq j$. This is because when an applicant grants market access to a member country, it would normally hurt other member countries who compete in the same market.

(4) $\partial\left(W_{1}+W_{2}+W_{3}\right) / \partial T_{i}>0$, or $\partial\left(W_{1}+W_{2}\right) / \partial T_{i}>\left|\partial W_{3} / \partial T_{i}\right|$. That is, trade liberalization by the applicant is globally welfare-improving.

In the appendix, we describe a "competing supplier model" with three countries and three goods where each country imports one good but exports two goods. The competing supplier model helps to motivate why it is desirable for the present model to capture the above features.

Let us now develop a model to capture features (1) to (4) above. Let there be a parameter 
$\phi_{i}$ that captures the heterogeneity among the member countries. Specifically, assume that $\phi_{i}$ increases with the size of country $i$ and its depth of trade relationship with the applicant country, i.e. $\phi_{1}>\phi_{2}$ if country 1 is larger than country 2 or country 1 has a deeper trade relationship with the applicant country. If country 1 and country 2 are symmetric, then $\phi_{1}=\phi_{2}$.

Furthermore, make the following assumptions:

(A) $\partial\left(W_{1}+W_{2}\right) / \partial T_{i}=-\lambda\left(\partial W_{3} / \partial T_{i}\right)$, where $\lambda>1$. That is, members' total gains from country 3's market opening to country i is always $\lambda$ times country 3's loss. This satisfies feature (4). ${ }^{3}$

(B) $\partial W_{i} / \partial T_{i}=\lambda \phi_{i}, i=1,2$. This satisfies feature (2). The motivation behind this assumption is that country size and the depth of trade relationship determine the country's increase in output (and therefore payoff) in response to the acceding country's market opening. For example, if 1 is a larger country or has more to export to the applicant's market and 2 is a smaller country or has less to export to the applicant, then when country 3 opens its market, country 1 will benefit more than country 2 does because it has larger production operations to benefit from country 3's market opening than country 2 does, even though country 3 gives the same market access concessions to 1 and 2 (i.e. even though there is MFN). The US, for example, benefits more, in absolute terms, from China's market opening than, say, Singapore does.

(C) $\partial W_{j} / \partial T_{i}=-\lambda \beta_{j}^{i} \phi_{j}(i, j=1,2$ and $i \neq j)$. An exogenous fraction $\beta_{j}^{i}$ of country $j$ 's marginal benefit is "stolen" by $i$ when country 3 makes concession to country $i$. Larger $\beta_{j}^{i}$ and $\beta_{i}^{j}$ imply that $\mathrm{i}$ and $\mathrm{j}$ compete more intensely in country 3 market. This satisfies feature (3).

(D) Assumptions (A), (B) and (C) together imply that $\partial W_{3} / \partial T_{i}=-(1 / \lambda) \partial\left(W_{1}+W_{2}\right) / \partial T_{i}=$ $-\phi_{i}+\phi_{j} \beta_{j}^{i}(i, j=1,2$ and $i \neq j)$ which is assumed to be less than zero so as to satisfy feature (1).

In the appendix, we calibrate the present model to the "competing supplier model" and obtain estimates of $\lambda, \beta$ and $\phi$, to demonstrate how theser parameters are related to the

\footnotetext{
${ }^{3}$ If political economy consideration induces a government to put more weight on the welfare of importcompeting firms, as will be the case if one adopts the "protection for sale" (Grossman and Helpman, 1994) line of argument, then $\lambda$ is reduced but $\phi_{i}$ would be larger for the same size of country $i$ and same depth of trade relationship. See footnote 12 .
} 
size of each country and the depth of trade relationship, among other things. Moreover, the present model can be used to calculate approximately the outcome of the tariff-reduction negotiations in a competing supplier model with and without MFN.

Based on the above assumptions, country 3's payoff after its concessions are made is

$$
W_{3}=U_{3}-\phi_{1}\left(T_{1}-\beta_{1}^{2} T_{2}\right)-\phi_{2}\left(T_{2}-\beta_{2}^{1} T_{1}\right)
$$

country 1's payoff is

$$
W_{1}=U_{1}+\lambda \phi_{1}\left(T_{1}-\beta_{1}^{2} T_{2}\right)
$$

while country 2's payoff is

$$
W_{2}=U_{2}+\lambda \phi_{2}\left(T_{2}-\beta_{2}^{1} T_{1}\right)
$$

The outcome of the accession negotiation, $T_{1}$ and $T_{2}$, must be such that $W_{1}, W_{2}, W_{3}>0$. Otherwise, one of the parties would not consent to the deal. This implies that $\phi_{i}\left(T_{i}-\beta_{i}^{j} T_{j}\right)>$ 0 for $i, j=1,2$ and $i \neq j$. We call $\phi_{1}\left(T_{1}-\beta_{1}^{2} T_{2}\right)$ and $\phi_{2}\left(T_{2}-\beta_{2}^{1} T_{1}\right)$ the costs and $U_{3}$ the benefit to the applicant from the accession. Similarly, $\left|U_{i}\right|(i=1,2)$ is called the cost and $\lambda \phi_{i}\left(T_{i}-\beta_{i}^{j} T_{j}\right)$ the benefit to member $i$ from the accession. The difference between the benefit and the cost is called the payoff to the country.

More generally, suppose there are $n-1$ existing members, call them countries 1 through $n-1$, and suppose country $n$ is the applicant country. Assume that $U_{i}<0$ for $i=1,2 \ldots, n-1$, $U_{n}>0$ and $\sum_{j} U_{j}>0$ for $j=1,2, \ldots, n$. We have

$$
W_{i}=U_{i}+\lambda \phi_{i}\left(T_{i}-\sum_{j \neq i} \beta_{i}^{j} T_{j}\right) \text { for } i \neq n
$$

and

$$
W_{n}=U_{n}-\sum_{i \neq n} \phi_{i}\left(T_{i}-\sum_{j \neq i} \beta_{i}^{j} T_{j}\right)
$$

Again, it must be true in equilibrium that $T_{i}-\sum_{j \neq i} \beta_{i}^{j} T_{j}>0(i, j=1,2, \ldots, n-1$ and $i \neq j)$ for the deal to satisfy all countries.

Refer back for now to the 3-country case. In the following analysis, we shall assume that $U_{1}, U_{2}$ and $U_{3}$ are exogenous, while $\phi_{i}, \beta_{i}^{j}$ and $\lambda$ are parameters. The quantities to be negotiated are $T_{1}$ and $T_{2}$. When there is MFN rule, the constraint $T_{1}=T_{2}=T$ is exogenously imposed. When there is no MFN, no exogenous constraint on the relationship between $T_{1}$ and $T_{2}$ exists. 
The assumption that $U_{1}, U_{2}$ and $U_{3}$ are exogenous is consistent with many club enlargement rules. For example, a country that joins the WTO would be able to obtain tariffs and market access concessions from existing members based on an equal-treatment principle. There are usually very little extra concessions that an applicant can bargain for. All new members get the same degree of market access in each of the existing member countries. This assumption captures the rules of WTO accession negotiations (see World Trade Organization 1995a, 1995b and 2005). On the other hand, how much concession the applicant has to make in the accession negotiations indeed vary enormously from case to case in practice. For example, very few people would doubt that China made a lot more market opening concessions when joining the WTO than, say, Latvia did (when measured in absolute monetary terms). Note that $U_{i}$ does not have to be proportional to $\phi_{i}$, since different member countries have different degrees of protectionism. For example, if a larger member country (say 1) is more protectionist against other members while a smaller member country (say 2 ) is less protectionist against other members, country 3 can actually get lower benefit from the market-opening of the larger country upon accession to the club. In that case, $\phi_{1}>\phi_{2}$ but $\left|U_{1}\right|<\left|U_{2}\right|$.

For those who are used to modeling trade liberalization as reduction in tariffs only in a trade model, the above specification may seem too simple or lacking the required structure. However, as discussed in footnote 1, the items to be negotiated in a trade bloc can include much more than tariffs. They include matters as diverse as investment, government procurement, services, intellectual property rights, capital control, and so on. Hence, a onedimensional index of market access, which affects payoffs linearly, may not be a bad first approximation. On the contrary, the modeling of trade liberalization as simply a reduction in tariffs fails to capture many aspects of market access liberalization. Moreover, the outcome of an analysis based on tariff reductions in a trade model can very well be dependent on the trade model used. Therefore, using a model with less structure than a formal trade model yet retaining the most essential features may yield useful insights which cannot be obtained from using a more structured trade model.

In the following analysis, we define $W_{i}^{M}$ and $W_{i}^{N}$ (where $i=1,2, \ldots, n$ ) as the payoff to country $i$ under negotiations with MFN and negotiations with No-MFN respectively, when the total number of countries including the applicant country is $n$. Country $n$ is designated as the applicant country. 


\section{$3 \quad$ Negotiations without MFN}

In accordance with the practice of many international trade clubs, such as the WTO, I assume that the concessions made by the applicant is determined by a series of bilateral negotiations. We shall use the Nash cooperative bargaining framework to model each bilateral negotiation. We assume that unanimous approval of the members is required for the applicant to join the club. Therefore, in case any of the bilateral negotiations fail, the payoffs to all countries would be zero. Consequently, the threat point of all bilateral negotiations is $(0,0) .{ }^{4}$ It can be easily shown that, if the negotiations are carried out sequentially, and the earlier negotiators can lock in the commitments of the applicant, then the distribution of payoffs among the members depends on the order of the negotiations, with the earlier negotiators getting higher payoffs. This would not be a desirable outcome for a club such as the WTO, since (i) it would be in the interest of the applicant not to lock in any deal until it has negotiated with all parties concerned; (ii) the countries who negotiate later would object to the applicant locking in deals with earlier negotiators, since they would be disadvantaged. In short, it is more reasonable to assume that "nothing is agreed until everybody has agreed". To capture this aspect of the accession negotiation, we define the solution to the grand negotiation as one such that, given the bargaining solutions of all other bilateral bargainings, each pair of countries that engage in a bilateral bargaining has no incentive to change their own bargaining solution. In other words, the solution of the grand negotiation is a Nash equilibrium with the strategy

\footnotetext{
${ }^{4} \mathrm{An}$ alternative way to model the threat point is to assume that in case the acceding country reaches bilateral agreements with some but not all members (of the Working Party, which consists of all interested WTO members), it can still enter the WTO with those negotiated agreements being honored. We argue, however, that this assumption does not reflect the operation of the real world. As a matter of fact, most bilateral agreements reached during the accession process are conditional on successful accession. They would become invalid if the accession application fails. Take the example of the Sino-US trade agreement signed at the end of 1999 as part of China's accession negotiations to the WTO. The fact is that the agreement would only be valid conditional on China's successful accession to the WTO. And successful accession normally requires the blessings of all the important members of the Working Party. Therefore, the appropriate threat point of China in a bilateral accession negotiation is that there is no agreement with any member (of the Working Party).
} 
space being the concessions $\left\{T_{1}, T_{2}, \ldots, T_{n-1}\right\}$ made by the applicant to the members. ${ }^{5} 6$

Note that the benefits that country 3 gets from countries 1 and 2 cannot be negotiated, since they are granted to all new members on an equal-treatment basis. Therefore, $U_{1}, U_{2}$ and $U_{3}$ are exogenous. We only focus on the concessions made by the applicant. Therefore, the quantities to be negotiated are $T_{1}$ and $T_{2}$.

For each bilateral negotiation, we shall adopt the Nash cooperative bargaining solution and assume that countries have the same bargaining power. ${ }^{7}$ Admittedly, bargaining power can affect the share of surplus obtained by the acceding country. This can possibly explain why some countries seem to get worse deals than others in their accession negotiations. However, our goal is not to explain the distribution of payoffs across acceding countries, but to explain the impacts of the MFN rule on the payoffs to all the countries concerned in a certain accession episode. So, without loss of generality, we assume the simple case that all

\footnotetext{
${ }^{5}$ This solution concept accords with the "Technical Note on the Accession Process: Note by the Secretariat" issued by the WTO (2005, 7th paragraph of Overview), which states that "Bilateral market access negotiations begin following the Applicant's submission of offers on concessions and commitments in the goods and services sectors. As the negotiations advance, these initial market access offers are revised to take account of the progress achieved or expected."

${ }^{6}$ It turns out that this solution is the same as the multilateral Nash bargaining solution whereby $T_{1}$ and $T_{2}$ are chosen to maximize the product of the surpluses of all three countries. Incidentally, this solution would converge to the same outcome as the multilateral bargaining described in Krishna and Serrano (1996) and Chae and Yang (1994). Imagine players standing next to each other in a circle. Chae and Yang (1994) describe a n-person bargaining game where, first of all, the first (randomly chosen) player makes an offer to the player on his left hand side in a bilateral bargaining. If the latter accepts, he exits the game with the offer in hand. Then the first player would proceed with making offer to the player on his left hand side now left in the game in another round of similar bilateral bargaining. The difference with our model is that if the offer is rejected, then the responder becomes the proposer in the next round of bilateral bargaining. This time the responder would again be the player to his left. Krishna and Serrano (1996) consider a multilateral bargaining game with $\mathrm{n}$ players. Imagine players standing next to each other in a circle. The first player is chosen randeomly, and he proposes the shares of every player. The players who accept his proposed shares would exit the game with the shares secured. Then, in the next round, the next player to the first's left hand side still left in the game would propose the shares of the rest of the players left in the game. Again, those players who accept their shares exit the game with their shares secured. Then the game goes on.

Both procedures yield equilibrium outcomes that approximate the Nash bargaining solution when the players are patient. Both yield unique perfect equilibria.

${ }^{7}$ That is, the bargaining problem between country 3 and country $\mathrm{i}$ is to solve $\max _{T_{i}}$ $W_{3}\left(T_{1}, T_{2}\right)^{\alpha} W_{i}\left(T_{1}, T_{2}\right)^{1-\alpha}$ where $i=1,2$. Equal bargaining power means that $\alpha=0.5$. The problem is equivalent to solving $\max _{T_{i}} W_{3}\left(T_{1}, T_{2}\right) \cdot W_{i}\left(T_{1}, T_{2}\right)$.
} 
countries have the same bargaining power. $^{8}$

The solution of the game is as follows. For any given $T_{1}$, there is an optimal $T_{2}$ which is a solution to the Nash bargaining between country 3 and country 2. This allows us to compute the best response function expressing $T_{2}$ as a function of $T_{1}$. Likewise, for any given $T_{2}$, there is an optimal $T_{1}$ that solves the Nash bargaining game between country 3 and country 1 . This gives us the best response function expressing $T_{1}$ as a function of $T_{2}$. In equilibrium, each country pair must be satisfied with its negotiation outcome given the negotiation outcome of all other country pairs. This satisfies the requirement that "nothing is agreed until everybody has agreed".

\section{Negotiation between Countries 2 and 3}

The Nash bargaining problem is given by $\max _{T_{2}} W_{3}\left(T_{1}, T_{2}\right) \cdot W_{2}\left(T_{1}, T_{2}\right)$, the long form of which is

$$
\max _{T_{2}}\left[U_{3}-\phi_{1}\left(T_{1}-\beta_{1}^{2} T_{2}\right)-\phi_{2}\left(T_{2}-\beta_{2}^{1} T_{1}\right)\right]\left[U_{2}+\lambda \phi_{2}\left(T_{2}-\beta_{2}^{1} T_{1}\right)\right]
$$

which is equivalent to

$$
\left.\max _{T_{2}}\left[U_{3}-\left(\phi_{1}-\beta_{2}^{1} \phi_{2}\right) T_{1}-\left(\phi_{2}-\beta_{1}^{2} \phi_{1}\right) T_{2}\right]\left[U_{2}+\lambda \phi_{2} T_{2}-\lambda \phi_{2} \beta_{2}^{1} T_{1}\right)\right]
$$

The first order condition is

$$
\left.\lambda \phi_{2}\left[U_{3}-\left(\phi_{1}-\beta_{2}^{1} \phi_{2}\right) T_{1}-\left(\phi_{2}-\beta_{1}^{2} \phi_{1}\right) T_{2}\right]-\left(\phi_{2}-\beta_{1}^{2} \phi_{1}\right)\left[U_{2}+\lambda \phi_{2} T_{2}-\lambda \phi_{2} \beta_{2}^{1} T_{1}\right)\right]=0 .
$$

$T_{2}$ can be solved from the first order condition above to obtain the best response function $T_{2}\left(T_{1}\right)$. The best response function represents the optimal bargaining solution between countries 2 and 3 given the bargaining solution between 1 and 3. Note that the second order condition $\phi_{2}-\beta_{1}^{2} \phi_{1}>0$, which is equivalent to $\partial W_{3} / \partial T_{2}<0$, is what we assumed to be true in feature (1) in section 2. Likewise, the second order condition for the negotiation between countries 1 and 3 is equivalent to $\partial W_{3} / \partial T_{1}<0$, which is assumed to be true.

Equation (1) can be re-written as

$$
\left(\phi_{2}-\beta_{1}^{2} \phi_{1}\right) W_{2}=\lambda \phi_{2} W_{3}
$$

\footnotetext{
${ }^{8}$ We could assume different countries have different bargaining powers, but the basic conclusions would not be affected.
} 


\section{Negotiation between Countries 1 and 3}

The bargaining problem here is given by $\max _{T_{1}} W_{3}\left(T_{1}, T_{2}\right) \cdot W_{1}\left(T_{1}, T_{2}\right)$, the long form of which is

$$
\max _{T_{1}}\left[U_{3}-\phi_{1}\left(T_{1}-\beta_{1}^{2} T_{2}\right)-\phi_{2}\left(T_{2}-\beta_{2}^{1} T_{1}\right)\right]\left[U_{1}+\lambda \phi_{1}\left(T_{1}-\beta_{1}^{2} T_{2}\right)\right]
$$

The first order condition is therefore

$$
\left.\lambda \phi_{1}\left[U_{3}-\left(\phi_{1}-\beta_{2}^{1} \phi_{2}\right) T_{1}-\left(\phi_{2}-\beta_{1}^{2} \phi_{1}\right) T_{2}\right]-\left(\phi_{1}-\beta_{2}^{1} \phi_{2}\right)\left[U_{1}+\lambda \phi_{1} T_{1}-\lambda \phi_{1} \beta_{1}^{2} T_{2}\right)\right]=0
$$

Again, the best response function (the optimal bargaining solution between countries 1 and 3 given the optimal bargaining solution between countries 2 and 3) can be solved from the above first order condition. In equilibrium both best response functions should be satisfied. Since there is no need to make use of the best response functions, we do not present their explicit forms here, but we only bear in mind that they can be calculated. Nonetheless, for the sake of completeness, we present the best response functions and the "stability" of the Nash equilibrium in the Appendix.

Equation (3) can be re-written as

$$
\left(\phi_{1}-\beta_{2}^{1} \phi_{2}\right) W_{1}=\lambda \phi_{1} W_{3}
$$

In order for countries 1 and 3 to be satisfied with their own bargaining solution given the bargaining solution of countries 2 and 3, and vice versa, it must be the case that both first order conditions (2) and (4) are satisfied, which in turn implies that

$$
W_{1}: W_{2}: W_{3}=\frac{\lambda \phi_{1}}{\phi_{1}-\beta_{2}^{1} \phi_{2}}: \frac{\lambda \phi_{2}}{\phi_{2}-\beta_{1}^{2} \phi_{1}}: 1 .
$$

Hence,

$$
\frac{W_{1}+W_{2}}{W_{3}}=\frac{\lambda \phi_{1}}{\phi_{1}-\beta_{2}^{1} \phi_{2}}+\frac{\lambda \phi_{2}}{\phi_{2}-\beta_{1}^{2} \phi_{1}}>2 \lambda
$$

Note that the ratio $\frac{W_{1}+W_{2}}{W_{3}}$ is an indicator of the applicant's payoff - a lower ratio signifies a higher payoff to the applicant, since the only reason the ratio is lower is that $\sum_{j}\left(\phi_{j}-\beta_{i}^{j} \phi_{i}\right) T_{j}$, the total amount of concessions the applicant grants to the members, is lower. 
Three conclusions emerge from the above results. First, country 3 gets lower payoff than either country 1 or 2 , since $\frac{W_{1}}{W_{3}}>\lambda>1$ and $\frac{W_{2}}{W_{3}}>\lambda>1$. Second, the distribution of payoffs is independent of $U_{1}, U_{2}$ and $U_{3}$. Third, as each of $\beta_{2}^{1}$ or $\beta_{1}^{2}$ gets larger, the acceding country has to make more concessions. That is, as the member countries compete more intensely in the applicant's market (for example, they all export similar goods to the applicant), the applicant has to give more concessions to the members. When a member country's benefit gets eroded more by its competitors as the applicant opens its market, it strengthens the former's bargaining position so it can demand more concessions from the applicant. Therefore, we have

Proposition 1. Without MFN, the acceding country gets a lower payoff than each of the member countries. Moreover, as the member countries compete more intensely in the acceding country market, the acceding country has to make more concessions to the members.

Define $\widetilde{W}_{1} \equiv \frac{W_{1}}{\lambda}, \widetilde{U}_{1} \equiv \frac{U_{1}}{\lambda}, \widetilde{W}_{2} \equiv \frac{W_{2}}{\lambda}, \widetilde{U}_{2} \equiv \frac{U_{2}}{\lambda}$. From the primitive definitions of $W_{1}, W_{2}$ and $W_{3}$ given in Section 2, it can be shown that

$$
\widetilde{W}_{1}+\widetilde{W}_{2}+W_{3}=\widetilde{U}_{1}+\widetilde{U}_{2}+U_{3}=U_{3}-\left|\widetilde{U}_{1}\right|-\left|\widetilde{U}_{2}\right| \equiv X
$$

where $X$ is the maximum payoff available to the applicant if it merely offers the existing members just enough to gain their willingness to allow its admission to the club. However, if we treat $\widetilde{W}_{1}, \widetilde{W}_{2}$ and $W_{3}$ as "normalized" indicators of the payoffs of the countries, $X$ can also be treated as the "size of the pie": We start with a total sum of the payoffs to all countries $\left(\widetilde{U}_{1}+\widetilde{U}_{2}+U_{3}\right)$ equal to $X$, and end up with a total sum of payoffs equal to $X$ after concessions by the applicant are made $\left(\widetilde{W}_{1}+\widetilde{W}_{2}+W_{3}\right)$, no matter what the concessions are. Moreover, any gains for each existing member must be at the expense of the applicant. Therefore, this is exactly like dividing a pie of fixed size. ${ }^{9}$

From (5), we can easily see that

$$
\widetilde{W}_{1}: \widetilde{W}_{2}: W_{3}=\frac{\phi_{1}}{\phi_{1}-\beta_{2}^{1} \phi_{2}}: \frac{\phi_{2}}{\phi_{2}-\beta_{1}^{2} \phi_{1}}: 1=\eta_{1}: \eta_{2}: 1
$$

\footnotetext{
${ }^{9}$ The only difference between this game and a zero sum game is that for each unit of payoff given up by the applicant, the bargaining opponent gets $\lambda>1$ units of payoff given up. That is, it is as if one unit of the applicant's payoff can be converted into $\lambda$ units of the member's payoff. Once the payoffs of the members are "normalized" by converting them into units of the applicant's payoff, the game is the same as dividing a pie of fixed size.
} 
where we define $\eta_{1} \equiv \frac{\phi_{1}}{\phi_{1}-\beta_{2}^{1} \phi_{2}}>1, \eta_{2} \equiv \frac{\phi_{2}}{\phi_{2}-\beta_{1}^{2} \phi_{1}}>1$.

Therefore, defining $W_{3}^{N}$ as the equilibrium value of $W_{3}$ with no MFN rule, we have, from (6) and (7),

$$
W_{3}^{N}=\frac{1}{1+\eta_{1}+\eta_{2}}\left(U_{3}-\left|\widetilde{U}_{1}\right|-\left|\widetilde{U}_{2}\right|\right)=\frac{X}{1+\eta_{1}+\eta_{2}}<\frac{X}{3}
$$

Therefore, country 3 gets less than $1 / 3$ of the pie when there is no MFN rule.

\section{Negotiations with MFN}

Suppose $T_{1}^{*}$ is the Nash bargaining solution of the negotiation between countries 1 and 3, subject to the constraint of MFN. The variable $T_{2}^{*}$ is similarly defined between countries 2 and 3. If country 3 gives MFN treatment to countries 1 and $2, T_{1}^{*}$ in fact sets the lower bound of the concession that country 1 gets from 3 . The concession that country 1 gets from 3 eventually can be augmented if the Nash bargaining solution $T_{2}^{*}$ between countries 2 and 3 is greater than $T_{1}^{*}$. The same applies to the negotiation between countries 2 and 3 .

\section{Negotiation between 2 and 3}

Consider a Nash bargaining between 2 and 3. Let $T_{2}^{*}$ be the Nash bargaining solution that sets the lower bound of what country 2 is willing to accept from country 3 subject to the constraint of MFN. Then, $T_{2}^{*}$ is the solution to $\max _{T_{2}} W_{3}\left(T_{1}, T_{2}\right) \cdot W_{2}\left(T_{1}, T_{2}\right)$ where $T_{1}=T_{2}$. Note that as countries 2 and 3 negotiate over $T_{2}$, they take into account the fact that any change in $T_{2}$ would affect $T_{1}$ one for one. The above problem is equivalent to

$$
\max _{T_{2}^{*}}\left[U_{3}-\phi_{1}\left(1-\beta_{1}^{2}\right) T_{2}^{*}-\phi_{2}\left(1-\beta_{2}^{1}\right) T_{2}^{*}\right]\left(U_{2}+\lambda \phi_{2}\left(1-\beta_{2}^{1}\right) T_{2}^{*}\right)
$$

which is equivalent to

$$
\max _{T_{2}^{*}}\left[U_{3}-\theta_{1} T_{2}^{*}-\theta_{2} T_{2}^{*}\right]\left(U_{2}+\lambda \theta_{2} T_{2}^{*}\right)
$$

where $\theta_{1} \equiv \phi_{1}\left(1-\beta_{1}^{2}\right)$ and $\theta_{2} \equiv \phi_{2}\left(1-\beta_{2}^{1}\right)$. Note that $\lambda \theta_{i}$ represents the marginal benefit $\partial W_{i} / \partial T_{i}$ that country $i$ can reap from the increased market access offered by the acceding country, taking into account the fact that each increased market access is available to all members on a MFN basis. On the other hand, $\theta_{i}$ represents the marginal cost $-\partial W_{n} / \partial T_{i}$ to the applicant of offering concessions to country i under MFN. 
Therefore, the first order condition is

$$
\lambda \theta_{2}\left[U_{3}-\left(\theta_{1}+\theta_{2}\right) T_{2}^{*}\right]-\left(\theta_{1}+\theta_{2}\right)\left(U_{2}+\lambda \theta_{2} T_{2}^{*}\right)=0
$$

\section{Negotiation between 1 and 3}

Consider now the Nash bargaining between 1 and 3. Let $T_{1}^{*}$ be the Nash bargaining solution that sets the lower bound of what country 1 is willing to accept from country 3 subject to the constraint of MFN. Then, $T_{1}^{*}$ solves $\max _{T_{1}} W_{3}\left(T_{1}, T_{2}\right) \cdot W_{1}\left(T_{1}, T_{2}\right)$ where $T_{1}=T_{2}$. This is equivalent to

$$
\max _{T_{1}^{*}}\left[U_{3}-\left(\theta_{1}+\theta_{2}\right) T_{1}^{*}\right]\left(U_{1}+\lambda \theta_{1} T_{1}^{*}\right)
$$

Therefore, the first order condition is

$$
\lambda \theta_{1}\left[U_{3}-\left(\theta_{1}+\theta_{2}\right) T_{1}^{*}\right]-\left(\theta_{1}+\theta_{2}\right)\left(U_{1}+\lambda \theta_{1} T_{1}^{*}\right)=0
$$

Now, it is clear that the equilibrium outcome of the negotiations subject to MFN is $T_{1}=T_{2}=T=\max \left[T_{1}^{*}, T_{2}^{*}\right]$.

It can be shown that the solutions to (9) and (10) are

$$
T_{1}^{*}=\frac{U_{3}}{2\left(\theta_{1}+\theta_{2}\right)}+\frac{\left|U_{1}\right|}{2 \lambda \theta_{1}}
$$

and

$$
T_{2}^{*}=\frac{U_{3}}{2\left(\theta_{1}+\theta_{2}\right)}+\frac{\left|U_{2}\right|}{2 \lambda \theta_{2}}
$$

so that

$$
T=\max \left[T_{1}^{*}, T_{2}^{*}\right]=\frac{U_{3}}{2\left(\theta_{1}+\theta_{2}\right)}+\frac{1}{2 \lambda} \cdot \frac{\left|U_{m}\right|}{\theta_{m}}
$$

where $\frac{\left|U_{m}\right|}{\theta_{m}} \equiv \max \left[\frac{\left|U_{1}\right|}{\theta_{1}}, \frac{\left|U_{2}\right|}{\theta_{2}}\right]$.

It is clear that the order of negotiations does not matter to the outcome. It can also be shown that

$$
T_{1}^{*}-T_{2}^{*}=\frac{1}{2 \lambda}\left(\frac{\left|U_{1}\right|}{\theta_{1}}-\frac{\left|U_{2}\right|}{\theta_{2}}\right)
$$

When $T_{1}^{*}>T_{2}^{*}$, country 1's negotiation outcome is binding, and we say that country 2 free-rides on country 1's stronger bargaining position. The above equation says that 
under MFN, country 1's negotiation outcome is binding iff its cost-benefit ratio $\left(\left|U_{1}\right| / \theta_{1}\right)$ under MFN is greater than that of country $2\left(\left|U_{2}\right| / \theta_{2}\right)$. The divergence between $T_{1}^{*}$ and $T_{2}^{*}$ comes from the "asymmetry" in cost-benefit ratio between countries 1 and 2 under MFN. In the simple symmetric case that $U_{1}=U_{2}$ and $\theta_{1}=\theta_{2}$ (which is true when $\phi_{1}=\phi_{2}$ and $\left.\beta_{1}^{2}=\beta_{2}^{1}\right), T_{1}^{*}$ and $T_{2}^{*}$ are equal. In this case, the applicant country does not have to give excess concession to the member country that free-rides the other one. In fact, there is no free-riding at all.

We now want to deduce conditions under which MFN favors the applicant country. Defining $W_{3}^{M}$ as the equilibrium value of $W_{3}$ under MFN rule, we have

$$
\begin{aligned}
W_{3}^{M} & =U_{3}-\left(\theta_{1}+\theta_{2}\right) T \\
& =\frac{U_{3}}{2}-\frac{\left(\theta_{1}+\theta_{2}\right)}{2 \lambda} \cdot \frac{\left|U_{m}\right|}{\theta_{m}}
\end{aligned}
$$

We compare the case with MFN and the one without MFN in the next section.

\section{Analysis}

It is more instructive to re-write (12) as

$$
\begin{aligned}
W_{3}^{M} & =\frac{1}{2}\left(U_{3}-\frac{\left|U_{1}\right|+\left|U_{2}\right|}{\lambda}\right)-\frac{\theta_{1}+\theta_{2}}{2 \lambda}\left(\frac{\left|U_{m}\right|}{\theta_{m}}-\frac{\left|U_{1}\right|+\left|U_{2}\right|}{\theta_{1}+\theta_{2}}\right) \\
& =\frac{1}{2} X-\frac{\theta_{1}+\theta_{2}}{2 \lambda}\left(\frac{\left|U_{m}\right|}{\theta_{m}}-\frac{\left|U_{1}\right|+\left|U_{2}\right|}{\theta_{1}+\theta_{2}}\right)
\end{aligned}
$$

where it is recalled that $X$ is the "size of the pie". From the above equation, it is clear that the share of surplus of the applicant is dependent not only on $X$ but also on the size distribution of $\left|U_{1}\right| / \theta_{1}$ and $\left|U_{2}\right| / \theta_{2}$. This is contrary to the case when there is no MFN rule, where $W_{3}^{N}$ is dependent on $X$ and not on the size distribution of $\left|U_{1}\right| / \theta_{1}$ and $\left|U_{2}\right| / \theta_{2}$ (see equation (8)).

The first term on the right hand side of the second line shows that the applicant gets half of "the size of the pie" if the member countries are symmetric. Since $\frac{1}{2} X$ is more than $\frac{1}{3} X$, which is in turn more than $W_{3}^{N}$, this shows that when the member countries are symmetric (i.e. $\frac{\left|U_{1}\right|}{\theta_{1}}=\frac{\left|U_{2}\right|}{\theta_{2}}$ ), the acceding country makes less concessions under MFN rule- without MFN rule, the applicant can only get less than a third of "the size of the pie" instead of one 
half. The second term on the right hand side is the adjustment for the asymmetry between the members. The adjustment is always negative, since it reflects how much extra concessions the applicant has to make because some member countries free-ride on the member country with the strongest bargaining power.

From (8) and (13), it is straightforward to show that country 3 gains more when MFN is in place than when it is not iff

$$
W_{3}^{M}-W_{3}^{N}=\left(\frac{1}{2}-\frac{1}{1+\eta_{1}+\eta_{2}}\right) X-\frac{\theta_{1}+\theta_{2}}{2 \lambda}\left(\frac{\left|U_{m}\right|}{\theta_{m}}-\frac{\left|U_{1}\right|+\left|U_{2}\right|}{\theta_{1}+\theta_{2}}\right)>0
$$

Equation (14) demonstrates the two effects that lead to the divergence between the case with MFN and without MFN. The first effect can be called the hardened bargainer effect. Since all countries have the foresight to realize that for each dollar that the applicant gives up to a member country, many more dollars have to be given up by the applicant to other member countries, MFN would harden the applicant's bargaining position. Therefore, the hardened bargainer effect tends to favor the applicant under MFN as opposed to no-MFN. The magnitude of this effect is $\left[1 / 2-1 /\left(1+\eta_{1}+\eta_{2}\right)\right] X$. As it turns out, it is proportional to the size of the pie, and increases with the intensity of competition between the members in the applicant's market. ${ }^{10}$

In the appendix, we calibrate the present model to the competing supplier model, focusing on tariff reductions as the concessions to be made by the applicant. I show how the size of the pie $X$ is related to the sizes of the countries and the depth of their trade relationship, and how $U_{1}, U_{2}, U_{3}$ are related to the sizes of the countries and the tariff reductions from the members that the applicant gets from joining the club. The hardened bargaining effect is also shown.

Define $\mu_{1}=\phi_{1}-\beta_{2}^{1} \phi_{2}$ and $\mu_{2}=\phi_{2}-\beta_{1}^{2} \phi_{1}$. It can be seen that $\mu_{i}$ is in fact equal to $\left|\partial W_{3} / \partial T_{i}\right|$. Now we can demonstrate more clearly the hardened bargainer effect by noting that, without MFN, when country 1 negotiates with country 3, their best response function is obtained from

$$
\max _{T_{1}}\left[U_{3}-\mu_{1} T_{1}-\mu_{2} T_{2}\right]\left[U_{1}+\lambda \phi_{1}\left(T_{1}-\beta_{1}^{2} T_{2}\right)\right] \quad \text { where } \quad \frac{d T_{2}}{d T_{1}}=0
$$

since in equilibrium the negotiating partners in this negotiation treat $T_{2}$ as given.

\footnotetext{
${ }^{10}$ Recall that $\eta_{i}=\frac{\phi_{i}}{\phi_{i}-\beta_{j}^{i} \phi_{j}}$ increases with $\beta_{j}^{i}$.
} 
On the other hand, with MFN, assuming symmetry between countries 1 and 2, the negotiation between countries 1 and 3 is binding, and the first order condition that determines $T_{1}$ is obtained from

$$
\begin{gathered}
\max _{T_{1}}\left[U_{3}-\mu_{1} T_{1}-\mu_{2} T_{1}\right]\left[U_{1}+\lambda \phi_{1}\left(T_{1}-\beta_{1}^{2} T_{1}\right)\right] \\
\Longleftrightarrow \max _{T_{1}}\left[U_{3}-\mu_{1} T_{1}-\mu_{2} T_{2}\right]\left[U_{1}+\lambda \phi_{1}\left(T_{1}-\beta_{1}^{2} T_{2}\right)\right] \quad \text { where } \frac{d T_{2}}{d T_{1}}=1 \text { is imposed. }
\end{gathered}
$$

That is, for each dollar given up by country 3 to country $1, \mu_{2} / \mu_{1}$ dollars are given up to country 2 too.

Therefore the two problems are of the same form, both being

$$
\max _{T_{1}}\left[U_{3}-\mu_{1} T_{1}-\mu_{2} T_{2}\right]\left[U_{1}+\lambda \phi_{1}\left(T_{1}-\beta_{1}^{2} T_{2}\right)\right]
$$

with the only difference being $\frac{d T_{2}}{d T_{1}}=0$ in the first case and $\frac{d T_{2}}{d T_{1}}=1$ in the second case. The first order condition of this generic problem is

$$
\begin{gathered}
-\left(\mu_{1}+\mu_{2} \frac{d T_{2}}{d T_{1}}\right) W_{1}+\lambda \phi_{1}\left(1-\beta_{1}^{2} \frac{d T_{2}}{d T_{1}}\right) W_{3}=0 \\
\Rightarrow \quad \frac{W_{3}}{W_{1}}=\frac{\mu_{1}+\mu_{2} \frac{d T_{2}}{d T_{1}}}{\lambda \phi_{1}\left(1-\beta_{1}^{2} \frac{d T_{2}}{d T_{1}}\right)} .
\end{gathered}
$$

From this we see that a larger $\frac{d T_{2}}{d T_{1}}$ leads to a higher $W_{3} / W_{1}$. Since a higher $W_{3} / W_{1}$ signifies less concessions made by country 3 to country 1 , the hardened bargainer effect is evident.

The second effect can be called free-rider effect, in the sense that any deal that the applicant makes with a member country can be made more unfavorable to the applicant by subsequent negotiations with other member countries. This would tend to hurt the applicant under MFN as opposed to no-MFN. This effect arises only when there is a difference between $\frac{\left|U_{1}\right|}{\theta_{1}}$ and $\frac{\left|U_{2}\right|}{\theta_{2}}$, which in turn leads to a difference between $T_{1}^{*}$ and $T_{2}^{*}$.

Which effect would dominate under asymmetry? One scenario when MFN favors the applicant is when free-rider effect is small. This will be the case when $\frac{\left|U_{1}\right|}{\theta_{1}}$ is sufficiently close to $\frac{\left|U_{2}\right|}{\theta_{2}}$. Therefore, we conclude that

Proposition 2. MFN favors the applicant if the distribution of the cost-benefit ratios of the members under MFN, $\left|U_{i}\right| / \theta_{i}$, is not too uneven under MFN, ceteris paribus. 
A special case where Proposition 2 applies is symmetry between countries 1 and 2: When $\frac{\left|U_{1}\right|}{\theta_{1}}=\frac{\left|U_{2}\right|}{\theta_{2}}$, the free-rider effect disappears.

From (8), we see that $W_{3}^{N}$ increases with $U_{3}$, everything else being equal. According to (14), since $W_{3}^{M}-W_{3}^{N}$ increases with $U_{3}$, while other terms in the equation are independent of $U_{3}$, we can conclude that MFN would favor the applicant as long as $U_{3}$ is sufficiently large. So, we state this result in

Proposition 3. MFN favors the applicant if its gross benefit from joining the club, $U_{3}$, is sufficiently large given $\left|U_{1}\right|$ and $\left|U_{2}\right|$, ceteris paribus.

The above proposition holds because the hardened bargainer effect would be larger when the "size of the pie" is larger, which is true when $U_{3}$ is larger, given $\left|U_{1}\right|+\left|U_{2}\right|$.

Next, since $X=U_{3}-\frac{\left|U_{1}\right|}{\lambda}-\frac{\left|U_{2}\right|}{\lambda}$, we can see that the RHS of (14) increases with $\lambda$. Therefore, we have the following proposition.

Proposition 4. MFN favors the applicant as long as $\lambda$ is sufficiently large, i.e. each member's benefit is sufficiently larger than the applicant's cost when the latter opens its market.

There are two explanations to Proposition 4. First, the hardened bargainer effect is larger when the "size of the pie" is larger, which is true when $\lambda$ is larger. Second, the free-rider effect is smaller the larger is $\lambda$. The intuition is that as each unit of payoff given up by the applicant is converted into more units of payoff for each member country, the latter would not be able to bargain as hard as before, resulting in the applicant having to make fewer concessions. The free-rider effect is smaller because the country with the strongest bargaining position bargains less hard than before, just like all other members. The size of the pie is larger because the maximum payoff available to the applicant when it makes just enough concessions to induce each member to allow its admission is now higher.

Finally, as each $\beta_{i}^{j}$ gets larger (say by increasing by the same factor), $\eta_{i}$ also gets larger, and more concessions has to be made by the applicant country without the MFN rule. According to (14), it makes it more likely that MFN favors the applicant. Therefore, we have 
Proposition 5. It is more likely that MFN favors the applicant as each $\beta_{i}^{j}$ gets larger, i.e. as member countries compete more severely in the acceding country's market.

The intuition is that for each dollar country 3 gives up to a member country, it gets back some cents from other member countries, and this weakens country 3's bargaining position when there is no MFN requirement. The more intense the competition between members in country 3's market, the more country 3 can get back from other member countries for each dollar it yields in a bilateral negotiation, and therefore the weaker is the bargaining position of country 3 without MFN rule.

\section{$6 \quad n$ countries}

The above propositions can be readily extended to the case with $n$ countries where $n>3$. Interestingly, we find that it is more likely that the hardened bargainer effect dominates the free-rider effect as $n$ increases by replication of existing types of member countries. Unless otherwise stated, let the operators $\sum_{i}$ denotes summation over all members, i.e. $\sum_{i} \equiv \sum_{i=1,2, \ldots, n-1}$.

\subsection{Negotiations without MFN}

\section{Negotiation between Countries $i$ and $n$}

The problem is given by

$$
\begin{gathered}
\max _{T_{i}} W_{n}\left(T_{1}, T_{2}, \ldots, T_{n-1}\right) \cdot W_{i}\left(T_{1}, T_{2}, \ldots, T_{n-1}\right) \\
\Longleftrightarrow \max _{T_{i}}\left[U_{n}-\sum_{i} \phi_{i}\left(T_{i}-\sum_{j \neq i} \beta_{i}^{j} T_{j}\right)\right] \cdot\left[U_{i}+\lambda \phi_{i}\left(T_{i}-\sum_{j \neq i} \beta_{i}^{j} T_{j}\right)\right] \\
\Longleftrightarrow \max _{T_{i}}\left(U_{n}-\sum_{j} \mu_{j} T_{j}\right)\left[U_{i}+\lambda \phi_{i}\left(T_{i}-\sum_{j \neq i} \beta_{i}^{j} T_{j}\right)\right]
\end{gathered}
$$

where $\mu_{j} \equiv-\partial W_{n} / \partial T_{j}=\phi_{j}-\sum_{k \neq j} \beta_{k}^{j} \phi_{k}$ for $j, k=1,2, \ldots, n-1$ and $j \neq k$. 
First order condition:

$$
\begin{aligned}
-\mu_{i} W_{i}+\lambda \phi_{i} W_{n} & =0 \\
\Rightarrow \quad\left(\phi_{i}-\sum_{k \neq i} \beta_{k}^{i} \phi_{k}\right) W_{i} & =\lambda \phi_{i} W_{n} \\
W_{i} & =\lambda \eta_{i} W_{n}
\end{aligned}
$$

where $\eta_{i} \equiv \phi_{i} /\left(\phi_{i}-\sum_{k \neq i} \beta_{k}^{i} \phi_{k}\right)$. Clearly, the second order condition, $\phi_{i}-\sum_{k \neq i} \beta_{k}^{i} \phi_{k}>0$, is satisfied as it is equivalent to $\partial W_{n} / \partial T_{i}<0$, which is assumed to be true so as to satisfy feature (1) in section 2 .

Summing the equation over all members, we have

$$
W_{n} \lambda \sum_{j} \eta_{j}=\sum_{j} W_{j}
$$

This equation, together with the definition of the "size of the pie" given by $X \equiv W_{n}+$ $\left(\sum_{j} W_{j}\right) / \lambda$, allow us to solve for $W_{n}$. Therefore, we can conclude that, with no MFN, $W_{n}$ is given by

$$
W_{n}^{N}=\frac{X}{1+\sum_{j} \eta_{j}}<\frac{1}{n} X \text { since } \eta_{j}>1 \text { for all } j .
$$

It shows that the applicant gets less than $1 / n$ of the size of the pie.

\subsection{Negotiations with MFN}

We have to find the largest $T_{k}$ that solves

$$
\max _{T_{k}}\left(U_{n}-T_{k} \sum_{j} \theta_{j}\right)\left(U_{k}+\lambda \theta_{k} T_{k}\right) \quad \text { for } k=1,2, \ldots, n-1
$$

where $\theta_{j}=\phi_{j}\left(1-\sum_{i \neq j} \beta_{j}^{i}\right)$. It is clear that $\lambda \theta_{j}$ represents the marginal benefit $\partial W_{j} / \partial T_{j}$ that country $j$ can reap from the increased market access offered by the acceding country, taking into account the fact that each increased market access is available to all members on a MFN basis. On the other hand, $\theta_{j}$ is the marginal cost $-\partial W_{n} / \partial T_{j}$ to country $n$ of offering concessions to country $j$ under MFN. Hence $\theta_{j}$ must be greater than zero so as to satisfy feature (1) of section 2 . 
The first order condition of the problem is given by:

$$
\begin{aligned}
& -\left(\sum_{j} \theta_{j}\right)\left(U_{k}+\lambda \theta_{k} T_{k}\right)+\lambda \theta_{k}\left[U_{n}-T_{k} \sum_{j} \theta_{j}\right]=0 \\
& \Longleftrightarrow\left(\sum_{j} \theta_{j}\right)\left(\lambda \theta_{k}+\lambda \theta_{k}\right) T_{k}=\lambda \theta_{k} U_{n}-U_{k} \sum_{j} \theta_{j}
\end{aligned}
$$

The second order condition is $\left(\sum_{j} \theta_{j}\right) \lambda \theta_{k}>0$ for all $k=1,2, \ldots, n-1$, a sufficient condition of which is $\theta_{k}>0$ for all $k=1,2, \ldots, n-1$. But this must be true by assumption as $\theta_{k}=-\partial W_{n} / \partial T_{k}>0$ must hold so as to satisfy feature (1) in section 2 .

Therefore, the solution of the maximization problem is given by

$$
\begin{aligned}
T_{k}^{*} & =\frac{\lambda \theta_{k} U_{n}-U_{k} \sum_{j} \theta_{j}}{2 \lambda \theta_{k} \sum_{j} \theta_{j}} \text { for } k=1,2, \ldots, n-1 \\
& =\frac{U_{n}}{2 \sum_{j} \theta_{j}}+\frac{\left|U_{k}\right|}{2 \lambda \theta_{k}}
\end{aligned}
$$

Suppose

$$
\frac{\left|U_{m}\right|}{\theta_{m}}=\max \left[\frac{\left|U_{1}\right|}{\theta_{1}}, \frac{\left|U_{2}\right|}{\theta_{2}}, \ldots, \frac{\left|U_{n-1}\right|}{\theta_{n-1}}\right]
$$

Then

$$
\begin{aligned}
T_{m}^{*} & =\max \left[T_{1}^{*}, T_{2}^{*}, \ldots, T_{n-1}^{*}\right] \\
& =\frac{U_{n}}{2 \sum_{j} \theta_{j}}+\frac{\left|U_{m}\right|}{2 \lambda \theta_{m}}
\end{aligned}
$$

Hence, with MFN in place, the payoff to the applicant, $W_{n}$, is given by

$$
\begin{aligned}
W_{n}^{M} & =U_{n}-T_{m}^{*}\left(\sum_{j} \theta_{j}\right) \\
& =\frac{U_{n}}{2}-\frac{\left|U_{m}\right|}{2 \lambda \theta_{m}}\left(\sum_{j} \theta_{j}\right) \\
& =\frac{1}{2} X-\frac{\sum_{j} \theta_{j}}{2 \lambda}\left(\frac{\left|U_{m}\right|}{\theta_{m}}-\frac{\sum_{j}\left|U_{j}\right|}{\sum_{j} \theta_{j}}\right)
\end{aligned}
$$

The first term on the right hand side of the last line shows the hardened bargainer effect, while the second term shows the adjustment to take into account the free-riders effect. 
The hardened bargainer effect allows the applicant to get a higher payoff under MFN rule under symmetry. Regardless of $n$, the applicant gets one half of the size of the pie under MFN if members are symmetric. This is greater than $X / n$ which is in turn greater than $W_{n}^{N}=X /\left(1+\sum_{i \neq n} \eta_{i}\right)$, the payoff without MFN. However, this payoff has to be adjusted for the extra concessions it has to make because of the asymmetry between the member countries.

\section{Comparison Between MFN and No-MFN}

It is immediately clear from (15) and (16) that

$$
W_{n}^{M}-W_{n}^{N}=\left(\frac{1}{2}-\frac{1}{1+\sum_{j} \eta_{j}}\right) X-\frac{\sum_{j} \theta_{j}}{2 \lambda}\left(\frac{\left|U_{m}\right|}{\theta_{m}}-\frac{\sum_{j}\left|U_{j}\right|}{\sum_{j} \theta_{j}}\right)
$$

In the following cases, when the distribution of $\frac{\left|U_{j}\right|}{\theta_{j}}$ is very skewed, we have $W_{n}^{M}-W_{n}^{N}<0$ : (1) $\left|U_{m}\right|$ is very large compared with all other $\left|U_{j}\right|$ where $j \neq m, n$; or (2) $\theta_{m}$ is very small compared with all other $\theta_{j}$ for $j \neq m, n$.

On the other hand, under symmetry, $\left|U_{m}\right| / \theta_{m}=\sum_{j}\left|U_{j}\right| / \sum_{j} \theta_{j}$. Then $W_{n}^{M}-W_{n}^{N}=$ $\left[1 / 2-1 /\left(1+\sum_{j} \eta_{j}\right)\right] X>0$.

Perhaps a more interesting result is that if $n$ increases by duplication of existing types of member countries, while $U_{n} / \sum_{j}\left|U_{j}\right|$ stays constant, then $W_{n}^{M}-W_{n}^{N}$ increases, and it is more likely that the applicant is favored by the MFN rule. ${ }^{11}$ For example, suppose there are two types of member countries: Type 1 corresponds to $\left|U_{1}\right|, \theta_{1}$ and Type 2 corresponds to $\left|U_{2}\right|, \theta_{2}$. Suppose there are $n_{1}$ Type 1 countries and $n_{2}$ Type 2 countries in the beginning, so that $1+\sum_{j} \eta_{j}=n_{1} \eta_{1}+n_{2} \eta_{2}+1$. If we duplicate the existing member countries, $1+\sum_{j} \eta_{j}$ becomes $2\left(n_{1} \eta_{1}+n_{2} \eta_{2}\right)+1$. Moreover, the fact that $U_{n} / \sum_{j}\left|U_{j}\right|$ stays constant implies that $U_{n}$ is doubled. Therefore $X$ is also doubled (the size of the pie doubles as the size of the club is doubled). As a result,

$$
\begin{aligned}
W_{n}^{M}-W_{n}^{N} & =\left(\frac{1}{2}-\frac{1}{2\left(n_{1} \eta_{1}+n_{2} \eta_{2}\right)+1}\right) 2 X-\frac{2 \sum_{j} \theta_{j}}{2 \lambda}\left(\frac{\left|U_{m}\right|}{\theta_{m}}-\frac{\sum_{j}\left|U_{j}\right|}{\sum_{j} \theta_{j}}\right) \\
& =2\left[\left(\frac{1}{2}-\frac{1}{2\left(n_{1} \eta_{1}+n_{2} \eta_{2}\right)+1}\right) X-\frac{\sum_{j} \theta_{j}}{2 \lambda}\left(\frac{\left|U_{m}\right|}{\theta_{m}}-\frac{\sum_{j}\left|U_{j}\right|}{\sum_{j} \theta_{j}}\right)\right] .
\end{aligned}
$$

\footnotetext{
${ }^{11}$ It makes sense to assume that the ratio of the benefit to the applicant to the total costs of the existing members to be constant, as the total benefits from trade should be higher with a larger trading bloc.
} 
The free-rider effect is doubled, but the hardened bargainer effect is more than doubled. Even if $W_{n}^{M}-W_{n}^{N}<0$ before, it is possible that $W_{n}^{M}-W_{n}^{N}>0$ now. Therefore, it is more likely that $W_{n}^{M}-W_{n}^{N}>0$.

Hence, we can state

Proposition 6. Propositions 1, 2, 34 and 5 all apply to $n>3$. Moreover, as $n$ increases by replication of existing types of members while $U_{n} / \sum_{j \neq n}\left|U_{j}\right|$ stays constant, the hardened bargainer effect strengthens relative to the free-rider effect, and the applicant is more likely to be favored by the MFN rule.

\section{Conclusion}

In this paper, we compare the effects of two different negotiation rules in club enlargement negotiation. In keeping with the rules of most international organizations, such as the WTO, NAFTA and the proposed FTAA, we assume that unanimous approval of existing (major) members is required for the applicant to join the club. We investigate the welfare implications of two different accession negotiation rules, namely the applicant conducting a series of bilateral negotiations with and without the MFN rule. When members are not too dissimilar, we find that negotiations without MFN induce the acceding country to liberalize trade more than with MFN.

When members are asymmetric, we find that there are two effects of the MFN rule, viz. the hardened bargainer effect and the free-rider effect. The former effect tends to favor the applicant (and hinders trade liberalization), while the latter effect tends to hurt the applicant (and enhances trade liberalization). We find that the latter effect is stronger the more uneven is the distribution of the cost-benefit ratios of the members under MFN. In particular, when the cost-benefit ratios are equal across all members, the free-rider effect disappears, and the MFN rule would unambiguously favor the applicant compared with the case without MFN rule. Moreover, if the "size of the pie" is sufficiently large, then the hardened bargainer effect would be large enough to dominate the free-rider effect, and the applicant is again favored by the MFN rule.

The above findings concerning the effects of MFN rule runs parallel to similar findings in the industrial organization and law \& economics literature. However, the results deviates from the typical ones obtained in the Rubinstein-type alternating-offer bargaining literature, 
where players negotiate to divide a pie of given size. In that literature, symmetry of the non-central players is almost always (implicitly) assumed. As we have seen in this paper, the result can be very misleading if we fail to account for the free-rider effect due to asymmetry of the non-central players.

Finally, another interesting and novel result is that, as the number of countries increases by duplication of existing types of member countries, it is more likely that the hardened bargainer effect dominates the free-rider effect. Therefore, bilateral negotiations with MFN is more likely to favor the applicant country as $n$ increases. That means the existing rule of accession negotiation in most international trade blocs, where bilateral negotiations with MFN are conducted, is more likely to favor the applicant in a large club than in a small one. 


\section{Appendixes}

\section{A A Competing Supplier Model}

In this appendix, we present a simple competing-supplier model to show that the features to be captured as listed in Section 2 are reasonable. First, we present the model; then we derive some properties of the model which are consistent with the features we want to capture as stated in the main text of the paper. Finally, we calibrate the model in the main text to this model.

Consider a three-country world in which each country imports one good from each of the two other countries. (The extension to n-country case is straightforward.) This model is useful for analyzing the role played by the MFN principle, since each country can impose different tariffs on different trading partners.

We assume that each country has an identical utility function $U=\sum_{i=1}^{3}\left(A \cdot D_{i}-0.5 \cdot D_{i}^{2}\right)+$ $D_{0}$, where $D_{i}$ denotes consumption of good $i$ and good 0 is the numeraire good. This utility function yields a demand function for the non-numeraire good $j$ in country $i$ of $D_{j}^{i}=A-P_{j}^{i}$, where $P_{j}^{i}$ is the domestic price of good $j$ in country $i$. Country $i$ is assumed to have a fixed endowment $x_{0}$ of good $0, y$ of good $i$ and an endowment $x$ (where $x>y$ ) of non-numeraire good $j \neq i$. Markets are perfectly competitive, as there are a large number of buyers and sellers in each market in all countries. Under these assumptions, it can be shown that the non-numeraire goods would each sell for a price of $A-(2 x+y) / 3$ in a free trade equilibrium, with country $i$ importing $(x-y) / 3$ units of good $i$ from each of the other countries. The numeraire good will not be traded under free trade, but is introduced to serve as a means of making transfers between the countries.

We assume that country $i$ 's only trade instrument is an import tariff. Since country $i$ is the only importer of good $i$ and only imposes tariffs on good $i$, we can drop the country superscript and let $t_{i j}$ be the specific tariff imposed on imports of good $i$ from country $j$. By definition, $P_{i}^{j}=P_{i}^{i}-t_{i j}$ (and $P_{i}^{k}=P_{i}^{i}-t_{i k}$ ) for $i \neq j \neq k$. This condition can then be substituted into the market clearing conditions to solve for $P_{i}^{i}$ and imports by country $i$ from country $j, M_{i j}$, 


$$
P_{i}^{i}=A-\left[\frac{2 x+y-t_{i j}-t_{i k}}{3}\right] ; \quad M_{i j}=\frac{x-y-2 t_{i j}+t_{i k}}{3}
$$

The expression for $M_{i k}$ can be derived similarly. An increase in $t_{i j}$ will improve the terms of trade of countries $i$ and $k$, but will worsen the terms of trade of country $j$.

It will be assumed that the trade negotiators choose tariffs to maximize a social welfare function of its own country. Tariff revenue, consumer welfare, and producer welfare all receive equal weight of one. Under this assumption, the national welfare function of country $i$ can be expressed as

$$
W^{i}\left(t_{12}, t_{13}, t_{21}, t_{23}, t_{31}, t_{32}\right)=\sum_{j=1}^{3} \frac{1}{2}\left(A-P_{j}^{i}\right)^{2}+\sum_{j \neq i} P_{j}^{i} x+P_{i}^{i} y+\sum_{j \neq i} t_{i j} M_{i j}+x_{0}
$$

The first term on the right hand side is consumer surplus, the second term is export sector revenue, the third term is import sector revenue, and the forth term represents tariff revenue.

In the absence of a trade agreement, the optimal tariff policy for country $i$ is obtained by choosing $t_{i j}(j \neq i)$ to maximize (17). It is straightforward to show that due to the symmetry between the countries, the optimal tariff policy will have equal tariffs on imports from all partners at a value given by

$$
t^{N}=\frac{x-y}{4} \text { and we have assumed that } \quad x-y>0
$$

Due to the separability of markets and the endowment pattern, the optimal trade policy of country $i$ is independent of tariffs set by other countries and (18) will be the tariffs in the non-cooperative Nash equilibrium. This reflects the standard prisoner's dilemma problem of trade policy, since all countries would gain by multilateral tariff reductions as long as the existing tariffs are below $t^{N}$. It can be easily shown that free trade would maximize world welfare, $\sum_{i=1}^{3} W^{i}$.

From (17), we can calculate 
(1)

$$
\begin{aligned}
\frac{\partial W^{i}}{\partial t_{i j}} & =(-1)\left(A-P_{i}^{i}\right) \frac{\partial P_{i}^{i}}{\partial t_{i j}}+y \frac{\partial P_{i}^{i}}{\partial t_{i j}}+M_{i j}+t_{i j} \frac{\partial M_{i j}}{\partial t_{i j}}+t_{i k} \frac{\partial M_{i k}}{\partial t_{i j}} \\
& =\frac{1}{9}\left[-11 t_{i j}+7 t_{i k}+x-y\right] \\
& >0 \text { if } x-y \text { is sufficiently larger than } t_{i j} \text { and } t_{i k}
\end{aligned}
$$

$$
\begin{aligned}
\frac{\partial W^{j}}{\partial t_{i j}} & =(-1)\left(A-P_{i}^{j}\right) \frac{\partial P_{i}^{j}}{\partial t_{i j}}+x \frac{\partial P_{i}^{j}}{\partial t_{i j}} \\
& =\frac{1}{9}\left(4 t_{i j}-2 t_{i k}-2 x+2 y\right) \\
& <0 \text { if } x-y \text { is sufficiently larger than } t_{i j} \text { and } t_{i k}
\end{aligned}
$$

$$
\begin{aligned}
\frac{\partial W^{k}}{\partial t_{i j}} & =(-1)\left(A-P_{i}^{k}\right) \frac{\partial P_{i}^{k}}{\partial t_{i j}}+x \frac{\partial P_{i}^{k}}{\partial t_{i j}} \\
& =\frac{1}{9}\left(t_{i j}-2 t_{i k}+x-y\right) \\
& >0 \text { if } x-y \text { is sufficiently larger than } t_{i j} \text { and } t_{i k}
\end{aligned}
$$

Let $i=3, j=1$ and $k=2$. As in the main text, countries 1 and 2 are assumed to be existing members while country 3 is the applicant. Note that increasing $t_{31}\left(t_{32}\right)$ is equivalent to decreasing $T_{1}\left(T_{2}\right)$ in the main text. Therefore, the signs of the above derivatives mirror the features to be captured as stated in Section 2 of the paper, namely, (1) $\frac{\partial W_{3}}{\partial T_{j}}<0$ for $j=1,2 ;(2) \frac{\partial W_{j}}{\partial T_{j}}>0$ for $j=1,2 ;(3) \frac{\partial W_{k}}{\partial T_{j}}<0$ for $j, k=1,2$ and $j \neq k$.

\section{A Calibration Exercise:}

Note that all countries are symmetric. Maintain the assumption that $i=3, j, k=1,2$, $j \neq k$, and let $t_{3 j}=t_{3 k}=t=(x-y) / 32$ before the accession negotiation. The negotiation is to lower $t$ from $(x-y) / 32$ downward (but not necessarily to zero). Therefore,

$$
\begin{aligned}
& \frac{\partial W^{3}}{\partial T_{j}}=\frac{\partial W^{3}}{\partial t_{3 j}}=\frac{1}{9}[-4 t+x-y]=\frac{1}{9}\left[\frac{7(x-y)}{8}\right]=(1-\beta) \phi \quad \text { for } j=1,2 \\
& \frac{\partial W^{j}}{\partial T_{j}}=\frac{\partial W^{j}}{\partial t_{3 j}}=\frac{1}{9}[2 t-2(x-y)]=\frac{-1}{9}\left[\frac{31(x-y)}{16}\right]=-\lambda \phi \quad \text { for } j=1,2
\end{aligned}
$$




$$
\frac{\partial W^{k}}{\partial T_{j}}=\frac{\partial W^{k}}{\partial t_{3 j}}=\frac{1}{9}(-t+x-y)=\frac{1}{9}\left[\frac{31(x-y)}{32}\right]=\lambda \beta \phi \quad \text { for } j, k=1,2, j \neq k
$$

Restrictly speaking, the derivatives are dependent on $t$. Note, however, that I have chosen a $t$ that is small enough compared with $x-y$ so that the magnitudes of the derivatives do not change much even as $t$ is lowered, and so I can assume that the above derivatives are more or less independent of $t$ as it is lowered. Therefore, we can solve that $\beta_{j}^{k}=\beta_{k}^{j}=\beta=0.5$ (for $j, k=1,2$ ), $\lambda=1.1$, and that $\phi$ can be any positive number. Since $\lambda>1$, trade liberalization does increase global welfare, which accords with the model in the main text. When translated into the notations in the main text of the paper, we have

$$
\frac{\partial W^{3}}{\partial T_{j}}=-0.5 \phi ; \quad \frac{\partial W^{j}}{\partial T_{j}}=1.1 \phi ; \quad \frac{\partial W^{k}}{\partial T_{j}}=-0.55 \phi .
$$

Note that $\phi=0.195(x-y) \cdot{ }^{12}$ Note also that $x-y$ reflects both the size of each economy and the depth of trade relationship between them: $x-y$ can be large only when $x$ is large (size of economies are large), and $x-y$ is large (they trade a lot). This accords with the characterization that $\phi$ increases with the size of the member country and its depth of trade relationship with the applicant country.

Assume that $t_{j 3}=t_{k 3}=t^{\prime}=(x-y) / 32$ and that $t_{j k}=t_{k j}=0$ (for $\left.j, k=1,2\right)$ before the accession negotiation. Then we can calculate the values of $U_{1}, U_{2}$ and $U_{3}$. If country 3 joins the club, it will get the treatment $t_{j 3}=t_{k 3}=0$ immediately, due to the equal treatment principle. Therefore,

$$
\begin{aligned}
& \frac{\partial W^{j}}{\partial t_{j 3}}=\frac{1}{9}\left[-11 t^{\prime}+x-y\right]>0 \quad \text { for } j=1,2 \\
& \frac{\partial W^{3}}{\partial t_{j 3}}=\frac{1}{9}\left[4 t^{\prime}-2(x-y)\right]<0 \quad \text { for } j=1,2
\end{aligned}
$$

\footnotetext{
${ }^{12}$ If we try to capture political economy by putting a weight $\alpha>1$ on the term $P_{i}^{i} y$ in the function $W^{i}$ in equation (17), as one would do following Grossman and Helpman's (1994) argument, then $\frac{\partial W^{i}}{\partial t_{i j}}=\frac{1}{9}\left[-11 t_{i j}+7 t_{i k}+x+(3 \alpha-4) y\right]$, but $\frac{\partial W^{j}}{\partial t_{i j}}$ and $\frac{\partial W^{k}}{\partial t_{i j}}$ remain unchanged. Therefore, $\frac{\partial W^{3}}{\partial T_{j}}=$ $\frac{1}{9}[-4 t+x+(3 \alpha-4) y]$ while $\frac{\partial W^{j}}{\partial T_{j}}$ and $\frac{\partial W^{k}}{\partial T_{j}}$ remain the same. Hence, the estimated $\phi$ would be higher than $0.195(x-y)$, and $\lambda$ would be less than 1.1. In other words, political economy consideration that makes the domestic government biased towards the welfare of the import-competing firms reduces $\lambda$ but increases $\phi$.
} 


$$
\frac{\partial W^{k}}{\partial t_{j 3}}=\frac{1}{9}\left(t^{\prime}+x-y\right)>0 \quad \text { for } j, k=1,2, j \neq k
$$

As $t^{\prime}$ is lowered from $(x-y) / 32$ to zero, we can easily calculate the change in welfare of each country as a consequence of the accession before country 3 makes its concessions to the member countries:

$$
\begin{aligned}
U_{3}=\triangle W^{3} & =\int_{t^{\prime}}^{0} \frac{1}{9}[4 \tau-2(x-y)] d \tau \\
& =-2 \times \frac{1}{9}\left\{\left[4 t^{\prime}-2(x-y)\right]-2(x-y)\right\} \frac{t^{\prime}}{2} \quad \text { where } t^{\prime}=(x-y) / 32 \\
& =2 \times \frac{1}{9}\left[\left(2(x-y)-\frac{4(x-y)}{32}\right)+2(x-y)\right] \frac{(x-y)}{64} \\
& =0.0135(x-y)^{2} \\
& =0.355 \phi^{2}
\end{aligned}
$$

$$
\begin{aligned}
& -U_{j} \quad \text { for } j=1,2 \\
= & -\triangle W^{j} \\
= & \int_{t^{\prime}}^{0} \frac{1}{9}[-11 \tau+x-y] d \tau+\int_{t^{\prime}}^{0} \frac{1}{9}[\tau+x-y] d \tau \\
= & \frac{1}{9}\left[\left(-11 t^{\prime}+x-y\right)+(x-y)\right] \frac{t^{\prime}}{2}+\frac{1}{9}\left[\left(t^{\prime}+x-y\right)+(x-y)\right] \frac{t^{\prime}}{2} \quad \text { where } t^{\prime}=(x-y) / 32 \\
= & \frac{1}{9}\left[\left(\frac{-11(x-y)}{32}+x-y\right)+(x-y)\right] \frac{(x-y)}{64}+\frac{1}{9}\left[\left((x-y)+\frac{x-y}{32}\right)+(x-y)\right] \frac{(x-y)}{64} \\
= & 0.0064(x-y)^{2} \\
= & 0.168 \phi^{2}
\end{aligned}
$$

Therefore, the size of the pie is

$$
X=\left(0.355-\frac{0.168 \times 2}{1.1}\right) \phi^{2}=0.0495 \phi^{2}
$$

Since $X>0$, there is surplus to be split among the three countries, which accords with the model in the main text.

Moreover, it is straightforward to calculate that $\eta_{1}=\eta_{2}=2$, so that with no MFN $W_{3}^{N}=\frac{X}{5}, \widetilde{W}_{1}^{N}=\frac{2 X}{5}, \widetilde{W}_{2}^{N}=\frac{2 X}{5}, W_{1}^{N}=\frac{2.2 X}{5}, W_{2}^{N}=\frac{2.2 X}{5}$, whereas under MFN we have 
$W_{3}^{M}=\frac{X}{2}, \widetilde{W}_{1}^{M}=\frac{X}{4}, \widetilde{W}_{2}^{M}=\frac{X}{4}, W_{1}^{M}=\frac{1.1 X}{4}, W_{2}^{M}=\frac{1.1 X}{4}$. Hence, the hardened bargainer effect is evident. There is no free-rider effect in this case as countries 1 and 2 are symmetric.

In general, if $t=k(x-y)$, then $\lambda=\frac{1-4 k}{1-2 k}>1$ (which demonstrates that trade liberalization is always good, consistent with our model); $\phi=\frac{2}{9}(x-y)(1-4 k)$ (which shows that if $k$ is small so that the there is more trade between the applicant and each member country to begin with, then $\phi$ is larger, which accords with our characterization of $\phi$ ); and $\beta=0.5$

all the time. If $t^{\prime}=k^{\prime}(x-y)$, then $U_{3}=\frac{4 k^{\prime}\left(1-k^{\prime}\right)(x-y)^{2}}{9}, U_{1}=U_{2}=-\left[\frac{4 k^{\prime}\left(1-2.5 k^{\prime}\right)(x-y)^{2}}{9}\right]$; therefore, $X=\frac{4 k^{\prime}(x-y)^{2}}{9}\left[\left(1-k^{\prime}\right)-\frac{1-2.5 k^{\prime}}{\lambda}\right]>0$. This shows that (i) the size of the pie is always positive, and (ii) the larger the countries, the larger is the pie, which accords with the model in the main text.

\section{B The Best Response Funcions}

Equation (1) is equivalent to

$$
\begin{aligned}
T_{2} & =\frac{\left[\lambda \phi_{2} U_{3}-\left(\phi_{2}-\beta_{1}^{2} \phi_{1}\right) U_{2}\right]-\lambda \phi_{2}\left[\left(\phi_{1}-\beta_{2}^{1} \phi_{2}\right)-\beta_{2}^{1}\left(\phi_{2}-\beta_{1}^{2} \phi_{1}\right)\right] T_{1}}{2 \lambda \phi_{2}\left(\phi_{2}-\beta_{1}^{2} \phi_{1}\right)} \\
& =\frac{\left[\lambda \phi_{2} U_{3}-\psi_{2} U_{2}\right]-\lambda \phi_{2}\left[\psi_{1}-\beta_{2}^{1} \psi_{2}\right] T_{1}}{2 \lambda \phi_{2} \psi_{2}}
\end{aligned}
$$

where $\psi_{1}=\phi_{1}-\beta_{2}^{1} \phi_{2}>0$ and $\psi_{2}=\phi_{2}-\beta_{1}^{2} \phi_{1}>0$. Name this best response function $T_{2}\left(T_{1}\right)$. It is assumed that $\phi_{1}-2 \beta_{2}^{1} \phi_{2} \geq 0$; consequently, $\psi_{1}-\beta_{2}^{1} \psi_{2}>0$ and so the best response function is downward sloping in $\left(T_{1}, T_{2}\right)$ space. Its slope is given by $d T_{2} /\left.d T_{1}\right|_{B R F_{2}}=$ $-\left[\psi_{1}-\beta_{2}^{1} \psi_{2}\right] / 2 \psi_{2}<0$.

Interchanging the subscripts (and superscripts) 1 and 2 in the above equation, we can obtain the best response function corresponding to equation (3):

$$
T_{1}=\frac{\left[\lambda \phi_{1} U_{3}-\psi_{1} U_{1}\right]-\lambda \phi_{1}\left[\psi_{2}-\beta_{1}^{2} \psi_{1}\right] T_{2}}{2 \lambda \phi_{1} \psi_{1}}
$$

Name this best response function $T_{1}\left(T_{2}\right)$. Similarly, it is assumed that $\phi_{2}-2 \beta_{1}^{2} \phi_{1} \geq 0$; consequently $\psi_{2}-\beta_{1}^{2} \psi_{1}>0$ and so the best response function is downward sloping in $\left(T_{1}, T_{2}\right)$ space too. Its slope is given by $d T_{2} /\left.d T_{1}\right|_{B R F_{1}}=-2 \psi_{1} /\left[\psi_{2}-\beta_{1}^{2} \psi_{1}\right]<0$. 


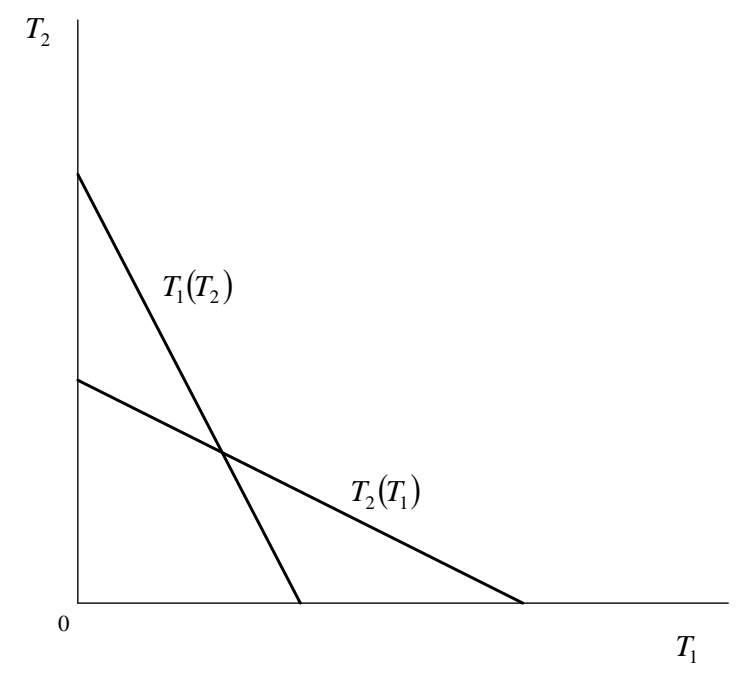

Figure 1: Nash equilibrium in bargaining outcomes. $T_{1}$ is the outcome of bargaining between countries 3 and $1 ; T_{2}$ is the outcome of bargaining between countries 3 and 2 .

Now,

$$
\begin{aligned}
& \left|\frac{d T_{2}}{d T_{1}}\right|_{B R F_{1}}-\left|\frac{d T_{2}}{d T_{1}}\right|_{B R F_{2}} \\
= & \frac{2 \psi_{1}}{\psi_{2}-\beta_{1}^{2} \psi_{1}}-\frac{\psi_{1}-\beta_{2}^{1} \psi_{2}}{2 \psi_{2}} \\
= & \frac{4 \psi_{1} \psi_{2}-\left(\psi_{1}-\beta_{2}^{1} \psi_{2}\right)\left(\psi_{2}-\beta_{1}^{2} \psi_{1}\right)}{2 \psi_{2}\left(\psi_{2}-\beta_{1}^{2} \psi_{1}\right)} \\
= & \frac{\psi_{1} \psi_{2}\left(3-\beta_{2}^{1} \beta_{1}^{2}\right)+\beta_{2}^{1}\left(\psi_{2}\right)^{2}+\beta_{1}^{2}\left(\psi_{1}\right)^{2}}{2 \psi_{2}\left(\psi_{2}-\beta_{1}^{2} \psi_{1}\right)}>0
\end{aligned}
$$

Therefore, the Nash equilibrium is stable. Figure 1 shows the best response functions. 


\section{References}

[1] Bond, Eric W., Stephen T. Ching, and Edwin L.-C. Lai (2003), "A Game-Theoretic Analysis of China's WTO Accession," Pacific Economic Review, 8: 2 (2003), pp.117125.

[2] Caplin, Andrew and Kala Krishna (1988), "Tariffs and the Most-Favored-Nation Clause: A Game Theoretic Approach," Seoul Journal of Economics 1: 267-289.

[3] Chae, Suchan and Jeong-Ae Yang (1994), "An N-Person Pure Bargaining Game," Journal of Economic Theory, 62: 86-102

[4] Cooper, Thomas E. (1986), "Most-Favored-Customer Pricing and Tacit Collusion," Rand Journal of Economics 17(3): 377-388.

[5] Cooper, T. and Fries, T. (1991) "The Most-Favored-Nation pricing policy and negotiated prices," International Journal of Industrial Organization 9, pp.209-223.

[6] Grossman, G. M. and E. Helpman (1994). Protection for sale. American Economic Review 84, 833-850.

[7] Horn, Henrik and Petros C. Mavroidis (2001), "Economic and Legal Aspects of the Most-Favored-Nation Clause", European Journal of Political Economy 17(2): 233-279.

[8] Horn, H. and Wolinsky, A. (1988), "Bilateral monopolies and incentives for merger," Rand Journal of Economics 19, pp. 408-419.

[9] Krishna, Vijay and Roberto Serrano (1996), "Multilateral Bargaining", Review of Economic Studies, 63: 61-80

[10] Ludema, Rodney (1991), "International Trade Bargaining and the Most-Favored-Nation Clause," Economics and Politics 3: 1-20.

[11] Rubinstein, Ariel (1982), "Perfect Equilibrium in a Bargaining Model," Econometrica 50(1): 97-109.

[12] Saggi, Kamal (forthcoming), "The MFN Clause, Welfare, and Multilateral Cooperation between Countries of Unequal Size," Journal of Development Economics 
[13] Salop, Steven C. (1986), "Practices that (Credibly) Facilitate Oligopoly Co-ordination," in Joseph E. Stiglitz and G. Frank Mathewson (eds), New Developments in the Analysis of Market Structure, MacMillan.

[14] Thompson, William (1994), "Cooperative Models of Bargaining," in R.J. Aumann and S. Hart (eds.), Handbook of Game Theory, Vol. 2.

[15] Spier, Kathryn E. "The Use of 'Most-Favored-Nation' Clauses in Settlement of Litigation," The RAND Journal of Economics, forthcoming.

[16] Suh, Sang-Chul and Quan Wen (2006) "Multi-Agent Bilateral Bargaining and the Nash Bargaining Solution," Journal of Mathematical Economics, Vol. 42, No. 1 (February 2006), 61-73.

[17] Suh, Sang-Chul and Quan Wen (forthcoming) "Mult-Agent Bilateral Bargaining with Endogenous Protocol," Economic Theory, forthcoming.

[18] World Trade Organization (1995a), "Accession to the World Trade Organization: Procedures for Negotiations under Article XII," WT/ACC/1.

[19] World Trade Organization (1995b), Guide to GATT Law and Practice, Geneva.

[20] - (200), "Technical Note on the Accession Process: Note by the Secretariat" WT/ACC/10/Rev.3, 28 November 2005. 